\title{
Identifikasi Patahan Lokal Menggunakan Metode Mikrotremor
}

\author{
Nizar Dwi Riyantiyo, Amien Widodo, dan Ayi Syaeful Bahri \\ Departemen Teknik Geofisika, Fakultas Teknik Sipil dan Perencanaan, Institut Teknologi Sepuluh Nopember (ITS) \\ e-mail: Syaeful_b@geofisika.its.ac.id
}

\begin{abstract}
Abstrak-Wilayah penelitian dalam studi ini adalah kota Surabaya sebagai ibu kota provinsi Jawa Timur. Penelitian ini akan difokuskan pada patahan lokal yang melintasi sungai kota surabaya, karena sungai Surabaya dilintasi beberapa jembatan di Surabaya seperti Dinoyo, Jagir, jembatan layang Wonokromo dan bendungan gunung sari. Berdasarkan kondisi geologi kota Surabaya berupa cekungan endapan aluvial dan batu pasir dengan sedimen batu lempung dan gamping, serta dilewati oleh sesar Kendeng yang bergerak 5 milimeter per tahun. Dengan komposisi endapan sedimen yang ada di Surabaya, wilayah yang memiliki kondisi geologi berupa aluvial, tuff, dan batu pasir akan memiliki potensi bahaya yang besar terhadapt intensitas getaran tanah akibat amplifikasi dan intensitas gempa. Sehingga tujuan dari dilakukannya penelitian ini adalah mengetauhui kondisi patahan lokal yang ada di sekitar sungai Surabaya, dimana ketika terkena guncangan gempa bumi dapat berpotensi bergerak dan dapat merusak infrastruktur disekitarnya. Metode yang digunakan dalam studi ini analisa Horizontal to Vertical Spectral Ratio (HVSR) untuk mendapatkan nilai frekuensi dominan kemudian akan diintegrasikan dengan nilai Vs30 untuk mendapatkan nilai kedalaman sedimen dan pada penelitian ini akan digunakan inversi HVSR untuk menggambarkan kondisi patahan lokal sungai Surabaya, sehingga dapat memprediksi zona bahaya disekitar patahan lokal sungai Surabaya.
\end{abstract}

Kata Kunci-Patahan Lokal, Mikrotremor, Horizontal to Vertical Spectral Ratio, Vs30, Kedalaman sedimen, Inversi HVSR.

\section{PENDAHULUAN}

$\mathbf{S}_{\mathrm{p}}^{\mathrm{L}}$ URABAYA berdasarkan kondisi geologi memilki struktur patahan lokal disekitar sungai Surabaya [1]. Patahan local tersebut melintasi jembatan layang Wonokromo, Dinoyo, Jagir, bendungan Gunung Sari, dan bendungan Jagir. Berdasarkan kondisi geologi kota Surabaya berupa cekungan endapan aluvial dan batu pasir dengan sedimen batu lempung dan gamping [1], serta dilewati oleh sesar Kendeng yang bergerak 5 milimeter per tahun, sesar Lasem berada di utara kota Surabaya $\pm 70 \mathrm{~km}$, sesar Watukosek di selatan Surabaya membentang dari Mojokerto hingga Madura $\pm 30 \mathrm{~km}$, sesar Grindulu berada di pantai selatan Pacitan sampai Mojokerto $\pm 50 \mathrm{~km}$. Dengan komposisi endapan sedimen yang ada di Surabaya, wilayah yang memiliki kondisi geologi berupa aluvial, tuff, dan batu pasir akan memiliki potensi bahaya yang besar terhadapt intensitas getaran tanah akibat amplifikasi dan intensitas gempa.

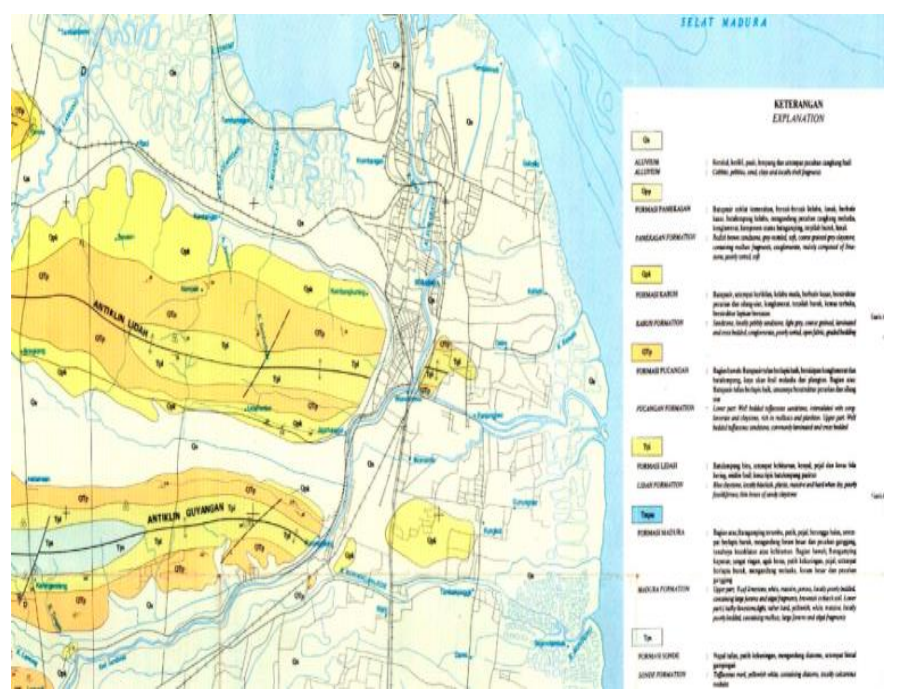

Gambar 1. Peta Geologi Surabaya (Sukardi, 1992)

Untuk mengurangi resiko bencana yang ada, maka dilakukan pengukuran mikrotremor dengan metode Horizaontal to Vertical Spectral Ratio (HVSR) di Kota Surabaya untuk memetakan lokasi rawan kerusakan akibat gempa (peta mikrozonasi). Menurut Nakamura [2] mengusulkan metode HVSR untuk mengestimasi frekuensi natural dan amplifikasi geologi setempat dari data microtremor.

Amplifikasi merupakan hasil pembesaran gelombang seismik akibat adanya kenaikan gelombang seismik yang diakibatkan kontras densitas yang besar antar lapisan, gelombang sesimik akan mengalami pembesaran ketika melewati medium yang lebih lunak dibandingkan dengan medium sebelumnya.

$$
A^{0}=\frac{\rho b \cdot v b}{\rho s . v s}
$$

Dengan nilai $\rho b$ merupakan densitas batuan dasar $(\mathrm{gr} / \mathrm{ml})$, vb cepat rambat gelombang batuan dasar, vs kecepatan rambat gelombang batuan lunak dan $\rho$ s densitas batuan lunak.

Kemudian penelitian yang mengangkat tema mengenai Mikrozonasi kota Surabaya oleh Bahri, dkk [3] dan [4] memiliki hasil dengan kecenderungan bahwa area yang memiliki tingkat kerentanan tinggi berada di wilayah bagian timur kota Surabaya. Hal ini diperkuat oleh penelitian yang dilakukan oleh Syaiffudin, dkk [5] tentang penelitian 
mikrotremor pada mud vulcano Gunung Anyar bahwa wilayah Surabaya timur memiliki kedalaman sedimen relatif dalam.

Berdasarkan penelitian yang dilakukan oleh Sungkono dan Santosa [6] yang telah melakukan pengolahan inversi kurva HVSR dengan mengestimasikan nilai kecepatan gelombang geser Vs, menunjukan bahwa kurva HVSR merepresentasikan karakteristik dinamik setempat. Nilai Vs yang didapatkan dari hasil inversi digunakan sebagai pengklasifikasian jenis tanah dan dapat digunakan sebagai indikasi zona bahaya akibat gempabumi.

\section{METODOLOGI PENELITIAN}

Penelitian ini digunakan alat mikrotremor jenis MAE terdiri dari Seismograf 3 komponen (2 komponen horizontal: EW-NS dan 1 komponen vertikal). Pengukuran mikrotremor dilakukan memotong patahan lokal dari barat ke timur kota surabaya sebanyak 40 titik. Alur penelitian ini secara lebih lengkap bisa dilihat pada gambar 2 .

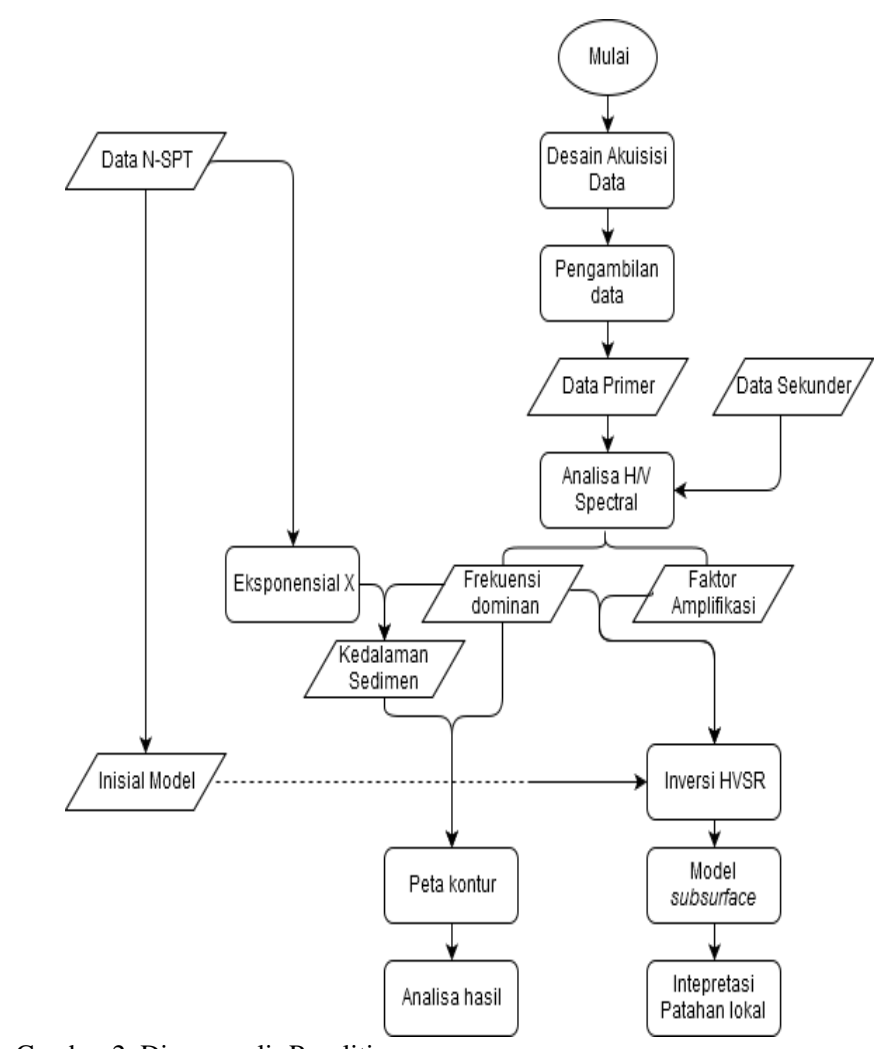

Gambar 2. Diagram alir Penelitian

Penelitian ini dimulai dari proses penghimpunan data sekunder dari PVMBG dan penelitian sebelumnya oleh Bahri, AS [3] dan [4]. Dari data tersebut diolah kembali untuk mendapatkan persebaran frekuensi dominan. Kemudian pada penelitian ini difokuskan kembali dengan adanya patahan lokal yang sejajar dengan sungai Surabaya.
Tabel 1.

Klasifikasi Tanah sesuai Eurocode 8

\begin{tabular}{|c|c|c|}
\hline $\begin{array}{c}\text { Tipe } \\
\text { tanah }\end{array}$ & Uraian Gambaran Stratigrafi & Vs30 (m/s) \\
\hline A & Batuan atau formasi batuan lainnya & $>800$ \\
\hline $\mathrm{B}$ & $\begin{array}{l}\text { Endapan sand atau clay yang sangat padat, } \\
\text { gravel, pada ketebalan beberapa puluh meter, } \\
\text { ditandai dengan peningkatan sifat fisik } \\
\text { mekanik terhadap kedalaman. }\end{array}$ & $360-800$ \\
\hline $\mathrm{C}$ & $\begin{array}{l}\text { Endapan sand padat atau setengah padat yang } \\
\text { tebal, gravel atau clay padat dengan ketebalan } \\
\text { beberapa puluhan hingga ratusan meter }\end{array}$ & $180-360$ \\
\hline $\mathrm{D}$ & $\begin{array}{l}\text { endapan tanah kohesi rendah sampai sedang } \\
\text { (degan atau tanpa beberapa lapisan kohesi } \\
\text { rendah), terutama pada tanah kohesi rendah }\end{array}$ & $<180$ \\
\hline $\mathrm{E}$ & $\begin{array}{c}\text { lapisan tanah terdiri dari aluvium pada } \\
\text { permukaan dengan nilai Vs tipe C atau D } \\
\text { degan ketebalan bervariasi } 5 \text { m hingga } 20 \\
\text { meter, dibawah tanah ini berupa material keras } \\
\text { dengan Vs }>800\end{array}$ & \\
\hline $\mathrm{S} 1$ & $\begin{array}{c}\text { Endapan terdiri dari atau mengandung, } \\
\text { ketebalan lapisan } 10 \mathrm{~m} \text { pada tanah lempung } \\
\text { lunak atau lempung lanauan dengan indeks } \\
\text { plastisitan dan kadar air yang tinggi }\end{array}$ & $\begin{array}{c}<100 \\
\text { (indikasi) }\end{array}$ \\
\hline $\mathrm{S} 2$ & $\begin{array}{l}\text { endapan tanah likuifiable, dari clay sensitif, } \\
\text { atau tanah lain yang tidak termasuk dalam tipe } \\
\text { A-E atau S1 }\end{array}$ & \\
\hline
\end{tabular}

\section{A. Pengolahan data mikrotremor}

Pengolahan data mikrotremor menggunakan analisa HVSR untuk mengestimasi frekuensi natural dan amplifikasi geologi setempat dari data microtremor [6]. Pengolahan data menggunakan software EasyHVSR. Tampak pada (gambar 3a) dilakukan pengolahan data menggunakan window stasioner 20 detik tanpa overlaping, setelah dilakukan windowing data akan melewati proses Fourier Transform untuk mengubah data berdomain durasi waktu menjadi domain frekuensi. Kemudian dilanjutkan dengan analisis HVSR untuk memperoleh nilai HVSR direpresentasikan oleh puncak kurva HVSR (gambar 4b) dan pada posisi tersebut didapatkan juga nilai frekuensi dominan. 

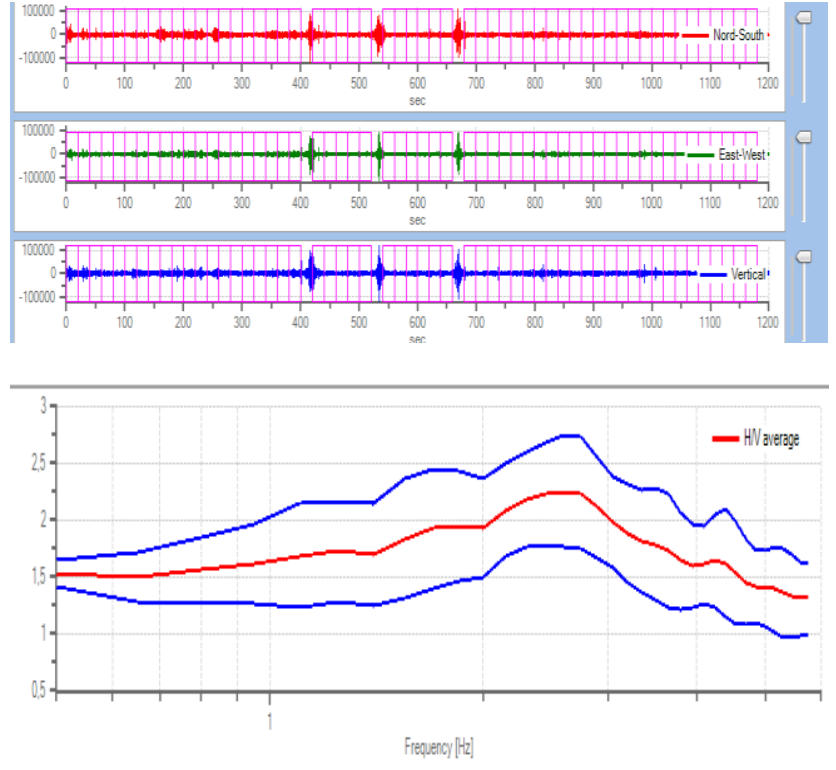

Gambar 3. Proses analisi data mikrotremor menggunakan metode HVSR, a. Data mikrotremor yang telah dilakukan windowing 20 detik tanpa overlaping, b. kurva HVSR membrikan informasi nilai amplifikasi dan frekuensi dominan.

\section{B. Penentuan Parameter Model}

Sebelum melakukan proses inversi, dibutuhkan sebuah pemodelan kedepan (forward modelling) yang menyatakan proses perhitungan "data" secara teoritis menggunakan persamaan matematik yang diturunkan dari konsep fisika yang mendasari fenomena yang ditinjau. Dalam pemodelan data geofisika, dicari suatu model yang menghasilkan respon yang cocok atau fit dengan data pengamatan atau data lapangan Grandis, H [7]. Dalam penelitian ini akan digunakan dua jenis data tebakan awal berupa nilai $\mathrm{Vp}, \mathrm{Vs}, \rho, \mathrm{H}, \mathrm{Qp}$ dan $\mathrm{Qs}$ dimana dalam proses penebakan ini beracuan pada data bor $\mathrm{N}$ SPT (data N-SPT Gunung Anyar dan data N-SPT komplek perumahan Citraland) yang dilakukan di kota Surabaya.

Dalam penentuan nilai Vs tebakan awal menggunakan konversi yang telah diajukan oleh Fauzi [8] Untuk penentuan nilai $\mathrm{Vp}$ digunakan asumsi $\mathrm{Vp}=2 \mathrm{Vs}$, dikarenakan saat dilakukan pendekatan dengan persamaan Brocher [9] terlalu besar untuk kondisi geologi kota Surabaya. Kemudian dalam penentuan densitas tiap lapisannya digunakan teori empiris Bowels, Foundation Analysis [10]. Dalam proses penentuan parameter Qp dan Qs digunakan nilai konstan dikarenakan kedua parameter tidak memiliki pengaruh besar terhadap kurva HVSR, diperkuat oleh Sungkono dan Santosa [6]

\section{Pengolahan inversi HVSR}

Setelah didapatkan nilai penebakan awal untuk proses inversi berupa nilai Vp, Vs, $\rho, \mathrm{H}$, Qp dan Qs, dilakukan proses inversi pada 43 titik pengukuran yang terdiri dari 25 data hasil pengukuran dan 18 oleh Bahri, AS [3] dan [4]. Program yang digunakan yaitu OpenHVSR untuk membantu proses inversi HVSR yang dikembangkan oleh Samuel [11].

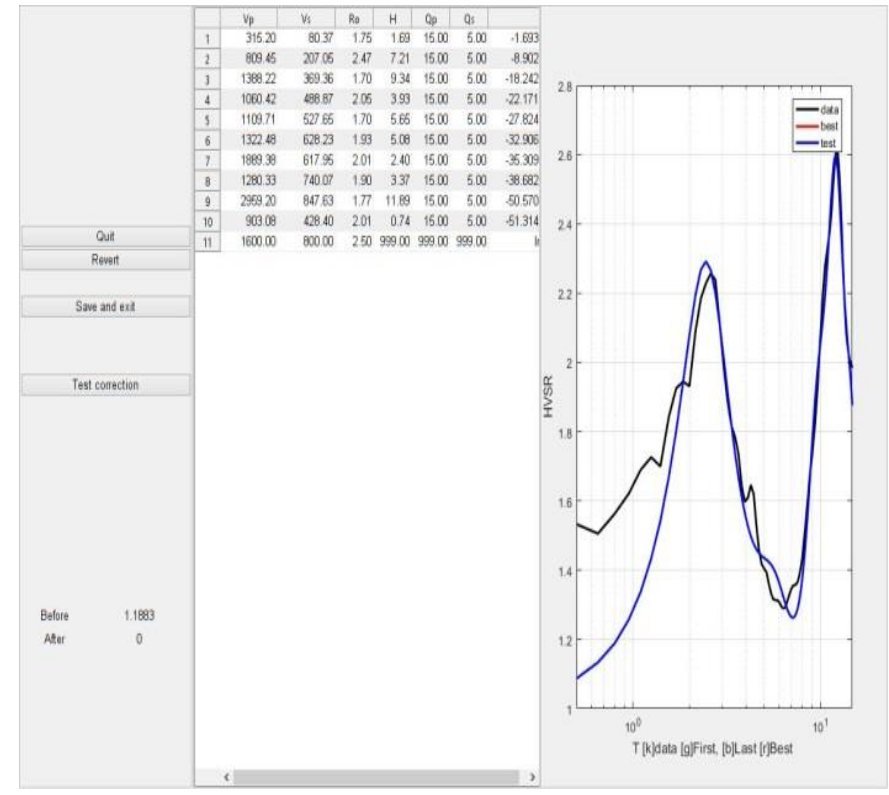

Gambar 4.Hasil Kurva Inversi titik TA12 dengan nilai RMS 1,18. Garis hitam mewakili kurva HVSR dan garis biru mewakili kurva hasil estimasi kurva HVSR dari model awal yang ditentukan sebelumnya.

\section{HASIL DAN PEMBAHASAN}

Setelah dilakukan analisa menggunakan metode Horizontal to Vertocal Spectral Ratio (HVSR) dengan tujuan untuk mendapatkan nilai frekuensi dominan di area penelitian dengan jumlah data 40 titik pengukuran, namun data yang memiliki tingkat reliable hanya 25 data sedangkan data pada titik lain tidak dapat di tentukan frekuensi yang reiable ini dapat disebabkan oleh adanya noise pada saat pengukuran (kendaraan bermotor).

Tabel 2.

Titik pengukuran dan nilai frekuensi dominan

\begin{tabular}{rcccc}
\hline \hline No & $\begin{array}{c}\text { Nama } \\
\text { Titik }\end{array}$ & $\mathrm{x}$ & $\mathrm{y}$ & frekuensi \\
\hline 1 & TA18 & 687036 & 9196695 & 2,62 \\
2 & TA17 & 688765 & 9195702 & 3,5 \\
3 & TA16 & 690618 & 9195022 & 2,65 \\
4 & TA15 & 690812 & 9194968 & Tidak reliable \\
5 & TA14 & 690942 & 9194857 & 2,9 \\
6 & TA13 & 690955 & 9194744 & 2,6 \\
7 & TA12 & 691035 & 9194646 & 2,6 \\
8 & TA11 & 691123 & 9194641 & 2,3 \\
9 & TA05 & 692813 & 9193820 & Tidak reliable \\
10 & TA33 & 686059 & 9195432 & 3,95 \\
11 & TA32 & 687697 & 9194469 & 3,8 \\
12 & TA31 & 689751 & 9193072 & Tidak reliable \\
13 & TA30 & 689836 & 9192931 & 3,35 \\
14 & TA29 & 689974 & 9192870 & 3,3 \\
15 & TA28 & 690039 & 9192841 & Tidak reliable \\
\hline \hline
\end{tabular}




\begin{tabular}{|c|c|c|c|c|}
\hline 16 & TA27 & 690263 & 9192697 & 2,9 \\
\hline 17 & TA26 & 690541 & 9192587 & Tidak reliable \\
\hline 18 & TA25 & 691524 & 9192314 & Tidak reliable \\
\hline 19 & TA01 & 695114 & 9192980 & 2,9 \\
\hline 20 & TA02 & 693946 & 9193249 & Tidak reliable \\
\hline 21 & TA03 & 692943 & 9193733 & Tidak reliable \\
\hline 22 & TA04 & 692898 & 9193791 & 3,5 \\
\hline 24 & TA06 & 692708 & 9193824 & Tidak reliable \\
\hline 25 & TA07 & 692526 & 9193913 & Tidak reliable \\
\hline 26 & TA08 & 692194 & 9193947 & Tidak reliable \\
\hline 27 & TA09 & 692342 & 9194037 & Tidak reliable \\
\hline 28 & TA37 & 685189 & 9189640 & 2,6 \\
\hline 29 & TA38 & 682501 & 9190080 & Tidak reliable \\
\hline 30 & TA39 & 688845 & 9188929 & 2,28 \\
\hline 31 & TA40 & 688743 & 9189114 & 2,3 \\
\hline 32 & TA41 & 688231 & 9189115 & 2,45 \\
\hline 33 & TA42 & 688030 & 9189093 & 2,75 \\
\hline 34 & TA43 & 687627 & 9189166 & Tidak reliable \\
\hline 35 & TA44 & 687319 & 9189331 & 4 \\
\hline 36 & TA19 & 694428 & 9190115 & 2,3 \\
\hline 37 & TA20 & 692972 & 9191014 & 2,15 \\
\hline 38 & TA21 & 692018 & 9191896 & 2,9 \\
\hline 39 & TA22 & 691859 & 9192006 & 3,45 \\
\hline 40 & TA23 & 691859 & 9192006 & 3,35 \\
\hline
\end{tabular}

Pada penelitian ini dilakukan sayatan 2 dimensi bawah permukaan untuk melihat kondisi bawah permukaan untuk nilai Vs dari tiap lapisan yang didapatkan.

Pada semua sayatan 2 dimensi (Gambar 5) dilakukan sayatan berarah barat-timur yang melewati Antiklin Lidah (Gambar 5). Berdasarkan klasifikasi tanah Eurocode 8 pada sayatan 1 ini lapisan yang dekat permukaan merupakan lapisan tipe E sesuai dengan (table. 1) yaitu lapisan aluvial dengan nilai Vs $50 \mathrm{~m} / \mathrm{s}$ hingga $100 \mathrm{~m} / \mathrm{s}$ pada rentang kedalaman 5-10 meter berwarna ungu pada (Gambar 5), dimana lapisan ini memiliki trend yang sama dengan kedalaman yang cenderung sama dari wilayah barat hingga timur kota Surabaya. Kemudian lapisan dibawahnya berturut-turut tipe $\mathrm{C}$ pada rentang nilai Vs $180 \mathrm{~m} / \mathrm{s}$ hingga $360 \mathrm{~m} / \mathrm{s}$ pada rentang kedalaman yang bervariasi $20 \mathrm{~m}$ hingga 90 meter dibawah permukaan ditandai kontur berwarna biru tua ke biru muda, kemudian tipe $\mathrm{D}$ dengan rentang nilai Vs $360-800 \mathrm{~m} / \mathrm{s}$ merupakan lapisan keras untuk kedalaman dari lapisan ini bervariasi 40 meter hingga 150 meter (sebagai batas bawah) ditandai dengan kontur berwarna hijau, kuning dan jingga.

\section{KESIMPULAN}

Hasil penelitian patahan lokal sungai Surabaya didapatkan nilai frekuensi dominan $2,1 \mathrm{~Hz}-4 \mathrm{~Hz}$, kedalaman sedimen 15 $\mathrm{m}-80 \mathrm{~m}$, kecepatan geser lapisan $50 \mathrm{~m} / \mathrm{s}-800 \mathrm{~m} / \mathrm{s}$. Hasil model bawah permukaan menunjukan bahwa sungai Surabaya terbentuk oleh patahan turun mengarah utara - selatan dan terlihat kemenrusannya.

\section{DAFTAR PUSTAKA}

[1] Sukardi, Geologi Lembar Surabaya \& Sapulu, Jawa. Pusat Penelitian dan Pengembangan Geologi. Pusat Penelitian dan Pengembangan Geologi, 1992.

[2] Y. Nakamura, A Method For Dynamic Characteristicsestimation Of Subsurface Using Microtremor On The Ground Surface, Quarterly. 1989.

[3] M. abied L. N. Bahri A, Syaeful, "Karakterisasi Kerusakan Bangunan Wilayah Jawa Timr Menggunakan Analisis Mikrotremor," Institut Teknologi Sepuluh Nopember Surabaya, 2013.

[4] dan D. N. A. Bahri A., Syaeful, Widya Utama, "Penaksiran Resonansi Tanah dan Bangunan Menggunakan Analisis Mikrotremor Wilayah Surabaya Jawa Timur," Institut Teknologi Sepuluh Nopember Surabaya, 2012.

[5] D. Syaifuddin, Firman, "Microtremor Study of Gunung Anyar Mud Volcano, Surabaya, East Java," in AIP Conference Proceedings, 2016.

[6] B. . S. Sungkono, "Karakterisasi Kurva Horizontal-To-Vertical Spectral Ratio: Kajian Literatur Dan Permodelan," Institut Teknologi Sepuluh Nopember Surabaya, 2011.

[7] H. Grandis, Pengantar Pemodelan Inversi Geofisika. Jakarta: Himpunan Ahli Geofisika Indonesia, 2009.

[8] dan U. J. F. Fauzi, Ahmad, Masyhur Irsyam, "Empirical Correlation Of Shear Wave Velocity And N-Spt Value For Jakarta," Int. J. GEOMATE, vol. 7, no. 1, pp. 980-984, 2014.

[9] T. M. dan J. D. Mavko, Gary, The Rock Physics Handbook: Tools For Seismic Analysis of Porous Media. Cambridge University Press, 2009.

[10] "http://www.soiltest.sienconsultant.com/," 2017. [Online]. Available: http://www.soiltest.sienconsultant.com/.

[11] S. Bignardi, OpenHVSR User Manual (Ver 2.0). 2016. 


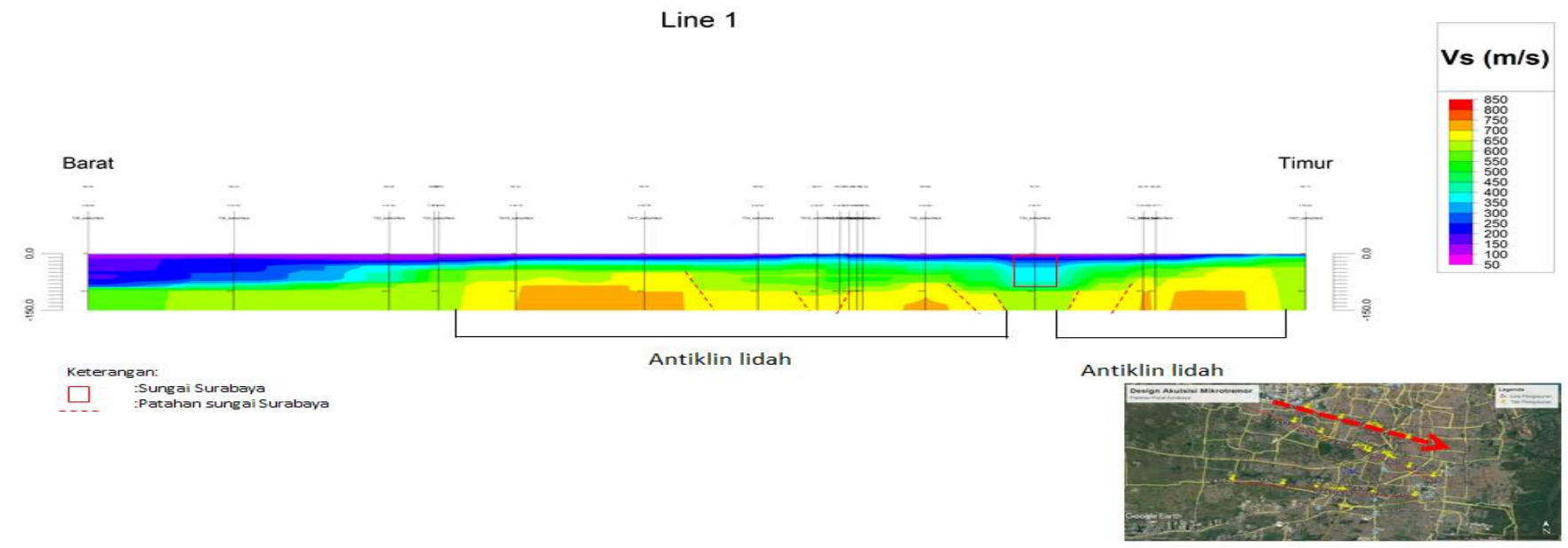

Gambar 5.Hasil inversi HVSR pada sayatan pertama dengan kedalaman maksimal 150 meter dan nilai kecepatan geser (Vs) 0-800 m/s 